\title{
COMPARISON OF HOSPITALIZATION RATE AND SOCIAL FUNCTIONING OF PATIENTS RECEIVING COMMUNITY MENTAL HEALTH SERVICE AND OUTPATIENT PSYCHIATRY POLICLINIC
}

\author{
Aydın Kurt ${ }^{1}$ \& Etem Erdal Erşan ${ }^{2}$ \\ ${ }^{I}$ Department of Psychiatry, Niğde Training and Research Hospital, Niğde, Turkey \\ ${ }^{2}$ Department of Psychiatry, Ömer Halisdemir University, Niğde, Turkey
}

received: 12.5 .2021 ;

revised: 21.7.2021;

accepted: 10.8 .2021

\begin{abstract}
SUMMARY
Background: This study aimed to compare the hospitalization rates and social functioning of patients receiving Community Mental Health Center (CMHC) services and those treated in the psychiatry policlinics of hospitals.

Subjects and methods: A total of 145 patients who were diagnosed with schizophrenia or schizoaffective disorder according to DSM-V criteria were included in the study. Of them, 81 received CMHC services at least for one year (CMHC group) and 64 were followed-up in psychiatry policlinics (hospital group). A personal information form containing socio-demographic and disease/treatment characteristics and hospitalization counts in the last year, Social Functioning Assessment Scale (SFAS) and Positive and Negative Syndrome Scale (PANSS) were used to collect data. The hospital group received antipsychotic medication therapy while a semi-structured psycho-social intervention program combined with antipsychotic drug therapy was applied in the CMHC group. The hospitalization counts, SFAS and PANSS scores of the groups were compared and the correlation of related factors were evaluated.

Results: Hospitalization rates were $0.21 \pm 0.56$ in the CMHC group and $1.03 \pm 1.31$ in the hospital group. The mean hospitalization rate was significantly lower in the CMHC group $(p<0.001)$. The mean scores for the overall SFAS and its interpersonal relationships and entertaining subscale; were significantly higher in the CMHC. The mean overall PANSS scores were $84.23 \pm 15.28$ and $99.50 \pm 15.99$ in the CMHC and hospital groups, respectively $(p<0.05)$. There was a moderate positive relationship between hospitalization rates and all PANSS scores.

Conclusions: CMHC services led to a serious decrease in hospitalization rates, increased the psychosocial functioning of patients and improved their compliance to treatment. Transition to a community-based mental health model should be accelerated for holistic treatment. Further longitudinal studies with a control group should be conducted.
\end{abstract}

Key words: CMHC - schizophrenia - hospitalization - social functioning

$* * * * *$

\section{INTRODUCTION}

Schizophrenia is a chronic and recurrent disease with positive, negative, emotional, behavioral and cognitive symptoms leading to impaired social and professional functioning (Stahl 2013). Although antipsychotic drugs play an indispensable and central role in the treatment of schizophrenia, antipsychotic treatment alone is not sufficient to improve negative symptoms, prevent relapses and enhance social and professional functioning (Penn et al. 2010). So, several psychosocial rehabilitation programs are implemented for the treatment and rehabilitation of schizophrenia and similar severe mental disorders. The application of psychosocial rehabilitation programs together with antipsychotic treatment helped to improve the symptoms of the disease, decrease the risk of exacerbation and frequency of hospitalization and enhance the social functioning of the patients (Hogarty et al. 1986, Y1ldiz et al. 2005, Aydin et al. 2014, Arslan et al. 2015, McGurk et al. 2017, Ersan 2020). The effectiveness is increased even more when such interventions are combined (Wykes et al. 2011).
Psychosocial rehabilitation is defined as the delivery of social, educational, vocational; behavioral and cognitive interventions applied to individuals with severe and permanent mental disorders to improve their social role performances (Anthony \& Liberman 1992). Improvement-focused models, social skills training, psycho-education programs training on the acquisition of problem-solving and coping skills, communitycoordinated support and family interventions, supported work and vocational programs and social life skills acquisition programs are the most widely used psychosocial interventions (Dixon et al. 2010, Dumont et al. 2018). With the changes in mental health policies that started in Italy in the $1960 \mathrm{~s}$, the transition from the hospital-based mental health model to the community-based mental health model began and spread rapidly within Europe and in the other parts of the world (Yanik 2007). Consequently, the transition to a community-based mental health system started in Turkey in 2008. Community Mental Health Centers (CMHC) were established to provide effective treatments for patients with severe mental disorders such as schizophrenia, bipolar disorder and other psychoses within the framework of community- 
based mental health model aimed at improving individual function and providing psychosocial support services, follow-ups and treatments as an integrated part of primary health care services in the environment where they live (Directive on Community Mental Health Centers, 2014).

In CMHCs in Turkey, treatment and follow-ups are carried out through the multi-dimensional psychosocial approach and outpatient services, psycho-education, social skills training; family education, occupational studies, health education; counseling services and individual and social activities. Additionally, awarenessraising training is provided, individual and family interviews are held and home visits are paid (Republic of Turkey Ministry of Health, National Mental Health Action Plan: 2011 -2023 2011, Dogan 2016, Songur et al. 2017). This model mainly aimed to reduce the duration and frequency of hospitalization of patients with severe mental disorders as much as possible, provide them with active treatment outside the hospital and ensure that they can manage to continue their lives without or with minimal support from others (Yanık 2007, Bilge et al. 2016). The decrease in the hospitalization rates thanks to $\mathrm{CMCHs}$ is considered as one of the most important indicators of their effectiveness (Liberman 2011, Alatas et al. 2009).

We claimed that the services provided by CMHCs are effective in decreasing the hospitalization rates and improving the psychosocial functioning of patients receiving these services. To show this, we compared the hospitalization rates in the last year and social functioning in patients with schizophrenia or schizoaffective disorder receiving CMHC services and those treated in the psychiatry units of hospitals. We also investigated the relationship between the hospitalization rates and social functioning of patients and sociodemographic and disease-related factors. Our results will be useful in determining the positive and deficient aspects of CMHC services on the social functioning of the patients and guiding future studies in this field.

\section{SUBJECTS AND METHODS}

The descriptive comparative study was carried out between March 15, 2019 and December 31, 2019 in the psychiatric outpatient clinics of Niğde Training and Research Hospital (NTRH) and the CMHC building affiliated to the hospital (Niğde CMHC). One hundred and forty-five patients diagnosed with schizophrenia or schizoaffective disorder who met the inclusion criteria were included in the study. Of them, 64 were followedup in NTRH psychiatric outpatient clinic (hospital group) and 81 received services from the Niğde CMHC (CMHC group).

Patients diagnosed with schizophrenia or schizoaffective disorder according to the DSM-5 (American Psychiatric Association's Diagnostic and Statistical Manual of Mental Disorders, Fifth Edition, 2013) diagnostic criteria, older than the age of 18 , who met the inclusion criteria and accepted to participate in the study were included. Only the patients who received services at the center for at least one year in the CMHC group were included in the study. Patients who received regular CMHC services and continued psychiatry outpatient clinic follow-up in the hospital group were excluded from the study. Patients that had a comorbid psychiatric disease, mental retardation, pervasive developmental disorder or any significant physical illness that may affect social functionality were excluded from the study.

\section{Data Collection Tools}

\section{A personal information form}

A personal information form was used to question the participants' socio-demographic characteristics such as age, sex, marital status; educational status and healthrelated characteristics such as the diagnosis and duration of the disease, the number of hospitalizations in the last year, medications used and depot antipsychotics and clozapine administration. This form was prepared by the researchers of the study.

\section{The Social Functioning Assessment Scale (SFAS)}

The Social Functioning Assessment Scale (SFAS) was developed by Yildiz et al. (2018) to assess the social functioning of Turkish patients. The scale was also tested for validity and reliability by them (Y1ldiz et al. 2018). This 19-item self-assessment scale included four subscales: self-care, interpersonal relationships and entertaining, independent living and work/occupation. A high scale score indicated high social functioning.

\section{Positive and Negative Syndrome Scale (PANSS)}

Positive and Negative Syndrome Scale (PANSS) was used to assess the severity of the symptoms in patients with schizophrenia. The scale consisted of three subdimensions and 30 items: positive symptoms (seven items), negative symptoms (seven items) and general psychopathology symptoms (16 items). Validity and reliability studies of the Turkish version of the scale were performed by Kostakoğlu et al. (1999) (Kostakoglu et al. 1999). A high score indicated a high severity of the symptoms.

\section{Study Design and Data Collection}

The patients diagnosed with schizophrenia or schizoaffective disorder and treated in the psychiatry policlinics of NTRH were defined as the hospital group and those who were followed-up in the Niğde CMHC were defined as the CMHC group.

Niğde CMHC is one of the first established CMHCs in Turkey and it started to provide services to patients with severe mental disorders such as schizophrenia, schizoaffective disorder and bipolar disorder in 2011. The number of patients registered to the Niğde CMHC was 598 during the study in 2019. Of them, 210 were diagnosed with schizophrenia and 18 with schizo- 
affective disorder and they were included in the CMHC group. Of these patients, 39 did not accept to participate in the study, 44 were registered to Niğde CMHC for less than one year, 27 were under the age of eighteen, 15 had comorbid mental retardation, 13 had serious physical illnesses and nine could not be reached. These patients were excluded from the study. In addition to drug therapy (mainly antipsychotic group drugs), psychosocial interventions such as psycho-education, occupational therapy, participation in social activities; having a case manager, automatic phone call reminder for the appointments and dates of long-acting antipsychotic injections and home visits were applied to the patients in Niğde CMHC.

The patients with the diagnosis of schizophrenia or schizoaffective disorder and who were followed-up in the NTRH psychiatry policlinics included in the hospital group. Many cases in this group were excluded from the study as they did not meet the inclusion criteria. We could not record the exact number of excluded patients in the hospital group due to intense working conditions in the psychiatry policlinics of NTRH. Only medication therapy was applied to this group.

Diagnosis of schizophrenia and schizoaffective disorder were made using semi-structured interviews based on the DSM-V criteria. A personal information form was used to collect the socio-demographic and diseaserelated data of the participants. The hospitalization counts of the participants in the past year in the psychiatric ward were determined from the patients' and their relatives' statements and by examining the hospital records. PANSS was used to assess the severity of the clinical symptoms. SFAS was filled by the patients to assess their social functioning states. For each patient, overall and subscale scores of PANSS and SFAS were calculated separately. The psychiatric evaluation and the application of the PANSS and the SFAS scales were completed in 60-90 minutes in two sessions with a mini break. Finally, the hospitalization rates and the social functionality of the groups were compared.

\section{Statistical Analysis}

Data were analyzed using the SPSS v23 package software program. The distribution of data was analyzed with the Kolmogorov Smirnov test. The skewness and kurtosis values of the data were checked and the histogram graph was examined. The Levene test was used to test the homogeneity of the variances. An independent groups $t$ test was used to compare the mean scores for the overall SFAS and its interpersonal relationships and entertaining and self-care subscales which had a normal distribution. The Mann-Whitney U test was used to compare the mean scores for the independent and non-normally distributed living and work/occupation subscales of the SFAS. Variables were examined at a $95 \%$ confidence level. A $p$ value less than 0.05 was significant.

\section{Ethical Issues}

The approval of the Ethics Committee of the Rectorate of Niğde Ömer Halisdemir University (27.02.2019/decision number: 2019/02-12) was obtained. The study was conducted according to the Declaration of Helsinki. All participants were informed about the study in detail and informed consent was obtained from either the patients or their legal guardians. The anonymity of the participants was preserved.

\section{RESULTS}

The socio-demographic characteristics of the patients were provided in Table 1 . Of the 145 participants, 100 were men and their mean age was $45.83 \pm 9.28$ and $41.19 \pm 11.87$ in the CMHC and hospital groups, respectively. There was no significant difference between the groups in terms of sex and educational, marital and employment statuses. However, the mean age of the participants in the CMHC group was significantly higher.

Disease- and treatment-related data of the groups were shown in Table 2. Of the participants, 126 were diagnosed with schizophrenia and the mean duration of the disease was $19.27 \pm 9.12$ and $16.11 \pm 10.09$ years in the CMHC and hospital groups, respectively. These data indicated the groups were similar in terms of diagnosis and duration of the disease, distribution of antipsychotic use and administration of depot antipsychotic. The mean scores of the groups were obtained from the overall PANSS and its positive, negative and general psychopathology subscales were given in Table 3. Mean scores for the overall PANSS and its subscales were significantly lower in the CMHC group $(p<0.05)$.

The number of hospitalizations which was $0.21 \pm 0.56$ in the CMHC group and $1.03 \pm 1.31$ in the hospital group in the last year was shown in Table 4. The average hospitalization rate in the last year was significantly lower in the CMHC group $(p<0.001)$.

The groups' mean scores for overall SFAS and its subscales were presented in Table 5. While the mean scores for the overall SFAS and interpersonal relationships and entertaining subscales were significantly higher in the CMHC group $(p<0.05)$, there was no significant difference between the groups in terms of their mean self-care, independent living and work/ occupation scores $(p>0.05)$.

Spearman correlation analysis was performed to investigate the relationship between the frequency of hospitalization and SFAS scores and the socio-demographic and treatment data. There was a positive weak correlation between the educational status and the mean scores for the overall SFAS and independent living subscale. There was a moderate positive correlation between the hospitalization rates and the mean scores for the overall PANSS and its subscales. There was no relationship between the socio-demographic and disease characteristics and the hospitalization rates or the mean SFAS scores. 
Table 1. The sociodemographic features of groups

\begin{tabular}{|c|c|c|c|c|c|}
\hline & \multicolumn{2}{|c|}{ CMHC Group } & \multicolumn{2}{|c|}{ Hospital Group } & \multirow[b]{2}{*}{$p$} \\
\hline & Mean & $\mathrm{Sd}$ & Mean & $\mathrm{Sd}$ & \\
\hline \multirow[t]{2}{*}{ Age } & 45.83 & 9.28 & 41.19 & 11.87 & $0.009 *$ \\
\hline & Number & $\%$ & Number & $\%$ & \\
\hline Gender & & & & & 0.720 \\
\hline Female & 24 & 29.6 & 21 & 32.8 & \\
\hline Male & 57 & 70.4 & 43 & 68.2 & \\
\hline Education & & & & & 0.285 \\
\hline Illiterate & 3 & 3.7 & 5 & 7.8 & \\
\hline Primary school & 40 & 49.4 & 26 & 40.6 & \\
\hline Middle school & 14 & 17.3 & 12 & 18.8 & \\
\hline High school & 22 & 27.1 & 15 & 28.4 & \\
\hline University & 2 & 2.5 & 6 & 12.2 & \\
\hline Marital status & & & & & 0.558 \\
\hline Single & 41 & 50.6 & 35 & 54.7 & \\
\hline Married & 23 & 28.4 & 20 & 31.3 & \\
\hline Widow/Divorced & 17 & 21 & 9 & 14 & \\
\hline Work status & & & & & 0.055 \\
\hline Working & 0 & 0 & 0 & 0 & \\
\hline Not working & 57 & 70.4 & 55 & 85.9 & \\
\hline Retired & 10 & 12.3 & 2 & 3.1 & \\
\hline Disabled retired & 14 & 17.3 & 7 & 11 & \\
\hline
\end{tabular}

Table 2. The illness and treatment datas of groups

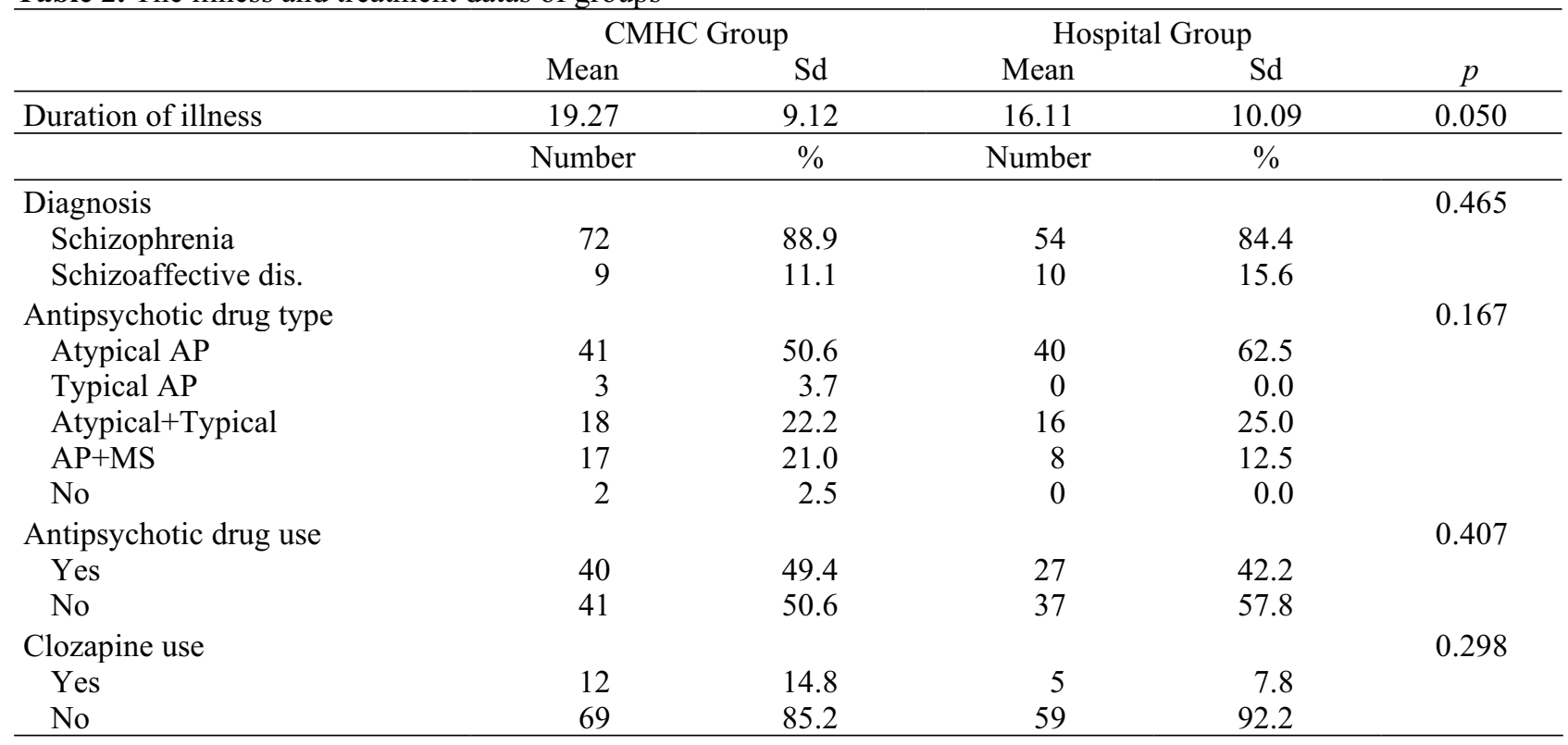

CMHC Group: Community Mental Health Center Group; AP: Antipsychotic; MS: Mood stabilizer; Sd: Standart deviation; $p$ : Statistical significance: \%: Percentage; An independent groups $t$ test was used to compare the duration of illness, Chi-square test was used for the analysis of categorical data (diagnosis, antipsychotic drug type, antipsychotic drug use, Clozapine use )

Table 3. The comparison of mean PANNS scores of groups

\begin{tabular}{lcccc}
\hline Mean PANSS Scores & CMHC Group (n:81) & Hospital Group (n:64) & $t$ & $p$ \\
\hline Total & $84.23 \pm 15.28$ & $99.50 \pm 15.99$ & 3.287 & $0.004^{*}$ \\
Positive & $17.74 \pm 5.98$ & $22.32 \pm 5.79$ & 2.378 & $0.015^{*}$ \\
Negative & $22.44 \pm 6.12$ & $26.23 \pm 6.95$ & 2.603 & $0.012^{*}$ \\
General Psychopathology & $44.05 \pm 7.60$ & $50.95 \pm 8.51$ & 1.838 & $0.039^{*}$ \\
\hline
\end{tabular}

PANSS: Positive and Negative Syndrome Scale; CMHC Group: Community Mental Health Center Group; n: Number $t$ : Critical value; $p$ : Statistical significance, ${ }^{*} p<0.05$; An independent groups $t$ test was used to compare the mean PANSS scores of groups. 
Table 4. The comparison of annuel hospitalization numbers of groups

\begin{tabular}{lcccc}
\hline & Median & $\%(25-75)$ & $z$ & $p$ \\
\hline CMHC Group (n:81) & 0.00 & $0.00-0.00$ & -4.688 & $<0.001^{*}$ \\
Hospital Group (n:64) & 1.00 & $0.00-2.00$ & & \\
\hline
\end{tabular}

CMHC Group: Community Mental Health Center Group, n: Number, \%: Percentiles, $z$ : Critical value, $p$ : Statistical significance, ${ }^{*} p<0.001$; The Mann Whitney U test was used to compare the mean annuel hospitalization numbers of groups.

Table 5. The comparison of mean SFAS scores of groups

\begin{tabular}{|c|c|c|c|c|c|c|}
\hline Mean SFAS Scores & \multicolumn{2}{|c|}{$\begin{array}{c}\text { CMHC Group (n:81) } \\
\text { Mean } \pm \text { Sd }\end{array}$} & \multicolumn{2}{|c|}{$\begin{array}{c}\text { Hospital Group (n:64) } \\
\text { Mean } \pm \text { Sd }\end{array}$} & $t$ & $p$ \\
\hline Total & & $1 \pm 6.44$ & & $3 \pm 7.62$ & 2.083 & $0.039^{*}$ \\
\hline Self care & & $1 \pm 2.56$ & & $3 \pm 2.66$ & 0.648 & 0.518 \\
\hline \multirow[t]{2}{*}{ Interpersonal relationships and entertaining } & & $5 \pm 3.12$ & & $7 \pm 3.40$ & 2.163 & $0.032 *$ \\
\hline & Med. & $\%(25-75)$ & Med. & $\%(25-75)$ & $z$ & $p$ \\
\hline Independent living & 10.00 & $6.00-11.00$ & 8.00 & $6.00-10.75$ & 1.538 & 0.106 \\
\hline Work/occupation & 1.00 & $1.00-1.00$ & 1.00 & $1.00-1.00$ & -0.146 & 0.815 \\
\hline
\end{tabular}

SFAS: Social Functionality Assesment Scale; CMHC Group: Community Mental Health Center Group, n: Number, Sd: Standart deviation, Med: Median, \%: Percentiles, $t$ : Critical value, $z$ : Critical value, $p$ : Statistical significance, ${ }^{*} p<0.05$, An independent groups $t$ test was used to compare the mean scores for the overall SFAS and its interpersonal relationships and entertaining and self-care subscales. The Mann Whitney U test was used to compare the mean scores for the independent living and work/occupation subscales of the SFAS.

\section{DISCUSSION}

Hospital-based mental health models and/or community-based mental health models are being applied in the management of severe mental disorders such as schizophrenia and schizoaffective disorder. The efficacy of these two important schools was compared in this study. The present study is among the scarce studies that directly compare the efficacy of the hospital-based mental health model and community-based mental health model.

We found that the average hospitalization rate in the last year was five times lower in the CMHC group and there was a moderate positive relationship between the hospitalization rates and the mean overall PANSS and subscale scores. The mean overall SFAS and interpersonal relationships and entertaining subscale scores were significantly higher in the CMHC group.

The mean number of hospitalizations was $0.21 \pm$ 0.56 in the CMHC group and $1.03 \pm 1.31$ in the hospital group. The last year's mean hospitalization rate was significantly lower in the CMHC group $(p<0.001)$. This finding was in line with other studies and the results of these studies show that routine CMHC services or similar psychosocial services reduce hospitalization rates at varying degrees (Wanchek et al. 2011, Iqbal et al. 2012, Chang et al. 2013, Aydın et al. 2014, Arslan et al. 2015, Ersan 2020).

One of the most important factors affecting the decrease in hospitalization rates is the increase in compliance to treatment. Noncompliance to treatment is a frequently encountered serious problem in clinical practices and can lead to frequent hospitalizations (dosReis et al. 2008, Çakır et al. 2010). Studies conducted with patients with schizophrenia revealed that they have less compliance to treatment than those with other medical diseases and non-compliance is a major problem (Cramer \& Rosenheck 1998). In their study, Weiden et al. (2004) studied 4325 patients with schizophrenia retrospectively between 1999 and 2001 and reported that non-compliance to treatment was the leading cause of hospitalizations (Weiden et al. 2004)

In the study conducted with schizophrenia patients at a CMHC, Üstün et al. (2018) stated that the duration of the disease and the number of hospitalizations increased as noncompliance to medication increased (Üstün et al. 2018). In the same study, compliance to treatment was better in patients with schizophrenia who participated in psychosocial rehabilitation programs than in those who did not. In Niğde CMHC, each participant had a case manager and they were in close contact with their families. Home visits were paid to all participants and to those who had bad compliance to treatment in particular. The participants and their relatives received psycho-education. These factors increased the patients' compliance to treatment and decreased the rates of hospitalization.

Psychosocial intervention programs in which cognitive behavioral therapy and homework were combined were reported to be more effective in increasing compliance to treatment than one-dimensional approaches (Haddad et al. 2014). In our study, we tried to provide semi-structured psycho-education, social skills training, occupational studies and other combined services to the participants at the CMHC. Psycho-education provided to patients and their relatives increased the insight and compliance to treatment and decreased hospitalization rates (Kopelowicz et al. 2012). In Niğde CMHC, educations on the disease and medicines and side effects of medicines were provided to the patients and their rela- 
tives by our health team. 'Patients' easy access to psychosocial support services such as CMHC increases their compliance to treatment and functioning and reduces hospitalization rates (Wanchek et al. 2011). Access to Niğde CMHC is relatively easy and the CMHC has a shuttle service which is actively used throughout the day to transport patients to and from the center.

Another way to improve compliance to treatment is the use of electronic reminders (Vervloet et al. 2012). In their multicenter randomized controlled longitudinal study conducted with 254 patients with schizophrenia, Montes et al. (2012) found that compliance to treatment was significantly better in patients who received automatically sent SMS messages (Montes et al.) In Niğde CMHC, a verbal message was regularly sent to the participants to remind them of their appointments and dates of long-acting antipsychotic injections. Sending verbal messages was a contributing factor to increase the participants' compliance to treatment and decrease the hospitalization rates in the CMHC group.

The type of antipsychotic drug used or the route of its administration affected the patient's compliance to treatment and the hospitalization rate. The hospitalization rate was lower in patients taking clozapine than those who took other antipsychotics (Pollack et al. 1998, Castro \& Elkis 2007). Using long-acting antipsychotic injections or even switching to long-acting antipsychotic injections in the early stages of the disease increases compliance and decreases the hospitalization rates (Lin et al. 2019; Munday et al. 2019). In our study, there was no significant difference between the groups in terms of the type of antipsychotic and clozapine administration rates. This resulted in a significant difference between the mean hospitalization numbers. The differences were attributed to the psychosocial interventions applied in Niğde CMHC.

Another leading factor affecting the hospitalization rate of schizophrenia patients is the severity of the symptoms. In the present study, the severity of the symptoms in the CMHC group was significantly lower than in the hospital group, which affected the hospitalization rates greatly. The lower severity of the symptoms experienced by the CMHC group was also related to the psychosocial rehabilitation services provided in the CMHC. Psychosocial rehabilitation services reduce the severity of symptoms of patients (Aydın et al. 2014, Arslan et al. 2015, Söğütlü et al. 2017, Şahin \& Elboğa 2019). One of the criteria for the patients to be included in the CMHC group in our study was to receive $\mathrm{CMHC}$ services for at least one year, which explains why the severity of the symptoms was lower in this group.

Another parameter we investigated was the social and community functioning of the participants. Although the mean overall SFAS and interpersonal relationships and entertaining subscale scores were significantly higher in the CMHC group, no significant difference was found between the groups' mean scores for the other subscales of the SFAS $(p>0.05)$. Reviews and meta-analyses investigating the effectiveness of various psychosocial interventions in patients with a severe mental illness such as schizophrenia or bipolar disorder reported these interventions to enhance patients' social functioning and help them gain social skills (Pfammatter et al. 2006, Arslan et al. 2015, Söğütlü et al. 2017, Dumont et al. 2018, Varga et al. 2018, Elboğa et al. 2019). This study showed that the CMHC services increased the psychosocial functioning of the patients and this was consistent with the findings in the literature.

The implementation of structured social skills training in which behavioral methods are used greatly affected the patients' social skills, behavioral approaches, made them feel more sociable and decreased hospitalization rates and the risk of recurrence of the disease (Benton \& Schroeder 1990). In their meta-analysis including 24 studies, Dumont et al. (2018) found that patients' awareness of their diseases was raised and their problem-solving skills improved after the implementation of interventions such as social skills training, traditional cognitive behavioral therapy and cognitive rehabilitation. These were followed by a decrease in positive and negative symptoms and aggressive behaviors and an increase in social and interpersonal skills (Dumont et al. 2018).

In the longitudinal study by Yildiz et al. (2005) investigating the effectiveness of psychosocial skills training in patients with schizophrenia, the patient and family groups consisting of 6-8 people received training once a week and once every two weeks, respectively. The patients' and their relatives' knowledge about schizophrenia increased significantly (Yildiz et al. 2005). Pfammatter et al. (2006) conducted a metaanalysis including 21 studies investigating the effectiveness of social skills training, cognitive rehabilitation, psycho-education for patients' relatives and cognitive behavioral therapy. The meta-analysis revealed that the psycho-education approach applied to patients' relatives reduced exacerbations and hospitalizations, social skill education had significant and lasting effects on skill acquisition, assertiveness and general psychopathology and cognitive rehabilitation and cognitive behavioral therapy had a positive effect on the results of the treatment (Pfammatter et al. 2006).

Contrary to these studies, in their meta-analysis of nine randomized and controlled studies including 471 patients with schizophrenia, Pilling et al. (2002) reported that structured social skills training did not positively contribute to the relapse rate of the disease, general compliance, social functioning; quality of life and compliance to treatment (Pilling et al. 2002). Wallace et al. (1980) reported that social skill training reduced patients' anxiety levels and led to some behavioral changes but did not cause any changes in their quality of life (Wallace et al. 1980). Dilk and Bond (1996) reported that although social skill training led to positive behavioral changes in patients, the reflection of 
these behavioral changes outside the research environment and their effects on the patient's life was not observed sufficiently (Dilk \& Bond 1996).

The patients participated in programs including structured psychosocial interventions such as social skill training for patients with schizophrenia (Bellack et al. 1997), multidimensional psychosocial intervention program (Arslan et al. 2015), psychosocial adaptation training (İlker et al. 2017) and psychosocial skills training (Yıldız et al. 2005, Söğütlü et al. 2017). Consistent with our study, some studies indicated that routine CMHC services and/or semi-structured interventions improved the psychosocial functioning of patients with schizophrenia (Ensari et al. 2013, Şahin \& Elboğa 2019). For instance, routine CMHC services provided in Bolu CMHC, which is the first CMHC in Turkey; improved the quality of life of patients with schizophrenia, reduced their disabilities and increased their social functioning (Ensari et al. 2013).

A multicenter CMHC study involving 198 patients with schizophrenia in Denmark compared the effectiveness of routine CMHC services with a structured psychosocial rehabilitation program called Disease Management and Recovery. There was no significant difference between the two treatment modalities in terms of social functioning, reduction of the severity of symptoms, substance abuse and hospitalization rates (Dalum et al. 2018).

The present study found no differences between the groups in terms of their mean scores for some of the SFAS subscales. This might be related to the mean age of the CMHC group and the duration of their illness. A high age and disease duration in schizophrenia patients worsen the cognitive destruction, which may lead to impaired social functioning (Harvey et al. 1999). In their longitudinal study conducted to compare the patients with schizophrenia and Alzheimer's disease and healthy individuals, Friedman et al. (2001) reported that the risk of impairment of cognitive and social functioning increased in line with the age (Friedman et al. 2001). A decline in cognitive functions may be observed with age even in healthy individuals. The scores obtained from the standardized mini mental test decreased by 1.4 points per year in the 11-year longitudinal study by Lyketsos et al. (Lyketsos et al. 1999).

\section{Study Limitations}

It was difficult to make a healthy comparison between the results of our study and others. The SFAS scale was filled in by patients as it was new and not used in many studies. Different scales were used in the literature (such as the Social Functioning Scale, the Global Assessment of Functioning Scale and the Clinical Global Impression) they were completed by the health personnel. It was difficult to compare the results of this cross-sectional study. A significant number of studies in the literature, in which the researchers could easily compare patients' pre- and post-study psychosocial functioning and observe individual changes, were longitudinal. If we compared the changes in patients' functioning between the beginning and end of the program, we could have obtained more significant results. As the CMHC group was required to receive $\mathrm{CMHC}$ services for at least one year the effects of this limitation were reduced to some extent.

Despite these limitations, routine CMHC services significantly reduced the hospitalization rates of those with schizophrenia or schizoaffective disorder and improved their psychosocial functioning. So, the role of psychosocial rehabilitation programs in the treatment of schizophrenia spectrum disorders patients is crucial.

\section{CONCLUSIONS}

CMHC services resulted in a significant decrease in hospitalization rates of schizophrenia or schizoaffective disorder patients and increased their psychosocial functioning. Although this result reveals the role of CMHC services in the treatment compliance of schizophrenia patients and psychosocial rehabilitation of the disease, CMHC services should be structured and extended to all CMHCs in Turkey to obtain more consistent and sustainable results. To provide patients with holistic treatment, the transition to a communitybased mental health model should be fulfilled as soon as possible and patients with a severe mental disorder should be encouraged to make use of CMHC services. Further longitudinal studies with a control group should be conducted.

\section{Acknowledgements: None.}

Conflict of interest: None to declare.

\section{Contribution of individual authors:}

Aydın Kurt: study design, patients enrollment, data collection, statistical analysis, manuscript preparation.

Etem Erdal Erşan: study design, patients enrollment, data collection, manuscript preparation.

\section{References}

1. Alatas G, Karaoğlan A, Arslan M \& Yanık M: Communitybased psychiatry model and project of community mental health centers in Turkey. Noro Psikiyatr Ars 2009; 46: Supp. 25-9

2. American Psychiatric Association (APA): Diagnostic and statistical manual of mental disorders, fifth edition (DSM5). 2013. Retrieved from: http://www.dsm5.org

3. Anthony WA \& Liberman RP: Principles and practice of psychiatric rehabilitation, in Handbook of Psychiatric Rehabilitation. Edited by Liberman RP. Mac-millan, New York. 1992 
4. Arslan M, Yazıcı A, Yılmaz T, Coskun S \& Kurt E: Longterm effects of a rehabilitation program on the clinical outcomes, social functionality, and life quality of schizophrenic patients - a follow-up study. Anatolian J Psychiatry 2015; 16:238-46. http://dx.doi.org/10.5455/apd.161411

5. Aydin E, Tabo A, Karamustafalıoğlu KO, Alataş G, Aydın $E$, Yiğit $S$ et al.: Revolving door phenomenon: the effect of application of community-based mental health services model at acute psychiatric hospitalization. Anatolian J Psychiatry 2014; 15:185-91. http://dx.doi.org/10.5455/apd.33996

6. Bellack AS, Mueser KT, Gingerich S \& Agresta J: Social skill training for schizophrenia a step by step guide. The Guilford Press, NY, 1997

7. Benton $M K \&$ Schroeder HE: Social skills training with schizophrenics: a meta-analytic evaluation. J Consult Clin Psychol 1990; 58:741-47. doi:10.1037/0022-006x.58.6.741

8. Bilge A, Mermer $G$, Çam O, Çetinkaya A, Erdoğan E \& $\ddot{U}$ çkuyu N: Profile of community mental health centers in Turkey between 2013-2015 years. Journal of Health Sciences of Kocaeli University, 2016; 2(2): 1-5. https://doi.org/10.30934/kusbed.358560

9. Castro $A P W \&$ Elkis $H$ : Rehospitalization rates of patients with schizophrenia discharged on haloperidol, risperidone or clozapine. Revista Brasileira de Psiquiatria 2007; 29(3). 207-12. doi:10.1590/s1516-44462007000300004

10. Chang L, Lin Y, Chang HW, Chen Y, Huang W, Liu CM et al.: Psychopathology, rehospitalization and quality of life among patients with schizophrenia underhome care case management in Taiwan. J Formos Med Assoc 2013; 112 : 208-15. https://doi.org/10.1016/j.jfma.2012.01.018

11. Cramer JA \& Rosenheck R: Compliance with medication regimens for mental and physical disorders. Psychiatr Serv 1998; 49(2): 196-201

12. Çakır F, Inem $C \&$ Yener F: Compliance to follow-up and treatment after discharge among chronic psychotic patients. Dusunen Adam The Journal of Psychiatry and Neurological Sciences 2010; 23: 50-9. DOI:10.5350/DAJPN2010230108t

13. Dalum HS, Waldemar AK, Korsbek L, Hjorthøj C, Mikkelsen JH, Thomsen $K$ et al.: Illness management and recovery: Clinical outcomes of a randomized clinical trial in community mental health centers. PLoS ONE 2018; 13(4): e0194027. https://doi.org/10.1371/journal. pone.0194027

14. Dilk MN \& Bond GR: Meta-analytic evaluation of skills training research for individuals with severe mental illness. J Consult Clin Psychol 1996; 64: 1337-46. doi:10.1037/0022-006x.64.6.1337

15. Dixon LB, Dickerson F, Bellack AS, Bennett M, Dickinson $D$, Goldberg RW et al.: The 2009 schizophrenia PORT psychosocial treatment recommendations and summary statements. Schizophr Bull 2010; 36:48-70. doi: 10.1093/schbul/sbp115

16. Doğan O: Social psychiatry practices in Turkey from yesterday to today. Anatolian J Psychiatry 2016; 17(2): 136-42. http://dx.doi.org/10.5455/apd.220090

17. dosReis S, Johnson E, Steinwachs D, Rohde C, Elizabeth A, Skinner EA et al.: Antipsychotic treatment patterns and hospitalizations among adults with schizophrenia. Schizophr Res 2008; 101:304-11. https ://doi.org/10.1016/j.schres.2007.12.475

18. Dumont M, Thériault J, Briand C, Dumais A \& Potvin S: Psychosocial approaches for individuals with schizophrenia in correctional and forensic psychiatric settings: a rapid review. Journal of Forensic Practice 2018; 20(3): 152-66. https://doi.org/10.1108/JFP-11-2017-0049
19. Elboğa G, Sahin SK \& Altında $\breve{g}$ A: Contribution of skills training in a community mental health center to daily living activities and cognitive functions. Current Approaches in Psychiatry 2019; 11(Suppl 1): 1-8. https ://doi.org/10.18863 Ipgy.53457 4

20. Ensari H, Gültekin BK, Karaman D, Koc A \& Beskardes $A F$ : The effects of the service of community mental health center on the schizophrenia patients: Evaluation of quality of life, disabilities, general and social functioning: $A$ summary of one year follow-up. Anatolian $J$ Psychiatry 2013; 14:108-14. https ://doi.org/10.5455/apd.36380

21. Erşan EE: Hospitalization and some sociodemographic characteristics of patients registered with a Community Mental Health Center. Community Ment Health J 2020; 56(3): 498-505. DOI 10.1007/s10597-019-00506-5

22. Friedman JI, Harvey PD, Coleman T, Moriarty PJ, Bowie C, Parrella $M$ et al.: Six-year follow-up study of cognitive and functional status across the lifespan in schizophrenia: a comparison with alzheimer's disease and normal aging. Am J Psychiatry 2001: 158:1441-48. doi:10.1176/appi.ajp.158.9.1441

23. Haddad PM, Brain C\& Scott J. Nonadherence with antipsychotic medication in schizophrenia: Challenges and management strategies. PROM 2014; 5: 43-62. https//doi.org/10.2147/PROM.S4273 5

24. Harvey PD, Silverman JM, Mohs RC, Parrella M, White L, Powchik $P$ et al.: Cognitive decline in late-life schizophrenia: a longitudinal study of geriatric chronically hospitalized patients. Biol Psychiatry 1999; 45:32-40. doi:10.1016/s0006-3223(98)00273-x

25. Hogarty GE, Anderson CM, Reiss DJ, Kornblith SJ, Greenwald DP, Javna CP et al.: EPICS Research Group. Family psychoeducation, social skills training, and maintenance chemotherapy in the aftercare treatment of schizophrenia, I: one-year effects of a controlled study on relapse and expressed emotion. Arch Gen Psychiatry 1986; 43; 633-42

26. Iqbal N, Nkire N, Nwachukwu I, Young $C \&$ Russell V: Home-based treatment and psychiatric admis-sion rates: Experience of an adult community mental health service in Ireland. Int J Psychiatry Clin Pract 2012; 16(4): 300-6. https://doi.org/10.3109/13651501.2012.687450

27. Ilker Ö, Şafak Y, Örsel S, Karaoğlan-Kahiloğulları A \& Karadağ H: Investigation of the efficacy of a psychiatricsocial rehabilitation performed In patients with schizophrenia in a community mental health center: Controlled study. Anatolian J Psychiatry 2017; 18:419-27. doi: 10.5455/apd.254450

28. Kopelowicz A, Zarate R, Wallace CJ, Liberman RP, Lopez $S R \&$ Mintz J: The ability of multifamily groups to improve treatment adherence in Mexican Americans with schizophrenia. Arch Gen Psychiatry 2012; 69(3): 265-73. https ://doi.org/10.1001/archg enpsy chiat ry.2011.135

29. Kostakoglu AE, Batur $S$ \& Tiryaki A: Positive and negative syndrome scale (PANSS) the validity and reliability of the Turkish version. Türk Psikoloji Dergisi 1999; 14(44): 23-32

30. Liberman PR: Yeti Yitiminden Iyileșmeye: Psikiyatrik Iyileştirim Elkitabı. M. Ylldı (Translate Ed.), Turkey: Türkiye Sosyal Psikiyatri Derneği Yayınları, Ankara, 2011

31. Lin CH, Chen FC, Chan HY \& Hsu CC: Time to rehospitalization in patients with schizophrenia receiving longacting injectable antipsychotics or oral antipsychotics. Int J Neuropsychopharmacol 2019; 22(9): 541-47. https ://doi.org/10.1093/ijnp/pyz035 
32. Lyketsos CG, Chen LS \& Anthony JC: Cognitive decline in adulthood: an 11.5-year follow-up of the baltimore epidemiologic catchment area study. Am J Psychiatry 1999; 156(1): 58-65. doi:10.1176/ajp.156.1.58

33. McGurk SR, Mueser KT, Watkins MA, Dalton CM \& Deutsch H: The feasibility of implementing cognitive remediation for work in community based psychiatric rehabilitation programs. Psychiatr Rehabil J 2017; 40(1): 79-86. http://dx.doi.org/10.1037/prj0000257

34. Montes JM, Medina E, Gomez-Beneyto M \& Maurino JA: Short message service (SMS)-based strategy for enhancing adherence to antipsychotic medication in schizophrenia. Psychiatry Res 2012; 200:89-95.

doi: 10.1016/j.psychres.2012.07.034

35. Munday J, Greene M, Chan E, Hartry A, Yan T \& Broder MS: Early initiation of long-acting injectable antipsychotic treatment is associated with lower hospitalization rates and healthcare costs in patients with schizophrenia: Real-world evidence from US claims data. Curr Med Res Opin 2019; 35:1231-39. https://doi.org/10.1080/03007995.2019.1571295

36. Pfammatter M, Junghan UM \& Brenner HD: Efficacy of psychological therapy in schizophrenia: conclusions from meta-analyses. Schizophr Bull 2006; 32(Suppl 1):S64-80. doi:10.1093/schbul/sbl030

37. Penn DL, Waldheter EJ, Perkins DO, Mueser KT \& Lieberman JA: Psychosocial treatment for first-episode psychosis: a research update. Am J Psychiatry 2010; 162:2220. https://doi.org/10.1176/appi.ajp.162.12.2220

38. Pilling S, Bebbington P, Kuipers E, Garety P, Geddes J, Martindale B et al.: Psychological treatments in schizophrenia: II. Metaanalyses of randomized controlled trials of social skills training and cognitive remediation. Psychol Med 2002; 32:783-91. doi:10.1017/S0033291702005640

39. Pollack S, Woerner MG, Howard A, Fireworker RB \& Kane $J:$ Clozapine reduces rehospitalization among schizophrenia patients. Psychopharmacol Bull 1998; 34:89-92

40. Songur C, Saylavcl E \& Kiran S: A comparative examination of mental health services on Europe and Turkey. Social Sciences Studies Journal 2017; 3:276-89

41. Söğ̈̈tlü L, Özen S, Varlık C \& Güler A: Psychosocial skill training applied to schizophrenia patients at community mental health center and the results. Anatolian J Psychiatry 2017; 18(2): 121-28. doi: 10.5455/apd.226040

42. Stahl SM: Stahl's Essential Pyschopharmacology. Neuroscientific Basis and Practical Applications. 4th edition. UK. 2013

43. Şahin Ş \& Elboğa G: Functioning, quality of life, treatment adherence and insight among patients who received community mental health center services. Cukurova Medical Journal
2019; 44:431-38. https://doi.org/10.17826/cumj.461779

44. T.C. Ministry of Health: T.C. Ministry of Health National Mental Health Action Plan: 2011-2023. 2011

45. T. C. Official Newspaper: Directive on Community Mental Health Centers, 9453, 06 March 2014

46. Üstün $G$, Küçük $L$ \& Buzlu S: Identifying the schizophrenia patients attending the rehabilitation program conducted in Community Mental Health Centers in terms of some demographic variables, characteristics related to the ailment, adaptation to the treatment and self-efficacies. Journal of Psychiatric Nursing 2018; 9(2): 69-79. https://doi.org/10.14744/phd.2018.87699

47. Varga E, Endre S, Bugya T, Tényi T \& Herold R: Community-based psychosocial treatment has an impact on social processing and functional outcome in schizophrenia. Front Psychiatry 2018; 9: 247. doi: 10.3389/fpsyt.2018.00247

48. Vervloet M, Linn AJ, van Weert JCM, de Bakker DH, Bouvy $M L \&$ van Dijk L: The effectiveness of interventions using electronic reminders to improve adherence to chronic medication: a systematic review of the literature. J Am Med Inform Assoc 2012; 19(5): 696-704. doi:10.1136/amiajnl2011-000748

49. Wallace CJ, Nelson CJ, Liberman RP, Aitchison RA, Lukoff $D$, Elder JP et al.: A review and critique of social skills training with schizophrenic patients. Schizophr Bull 1980; 6: $42-63$

50. Wanchek TN, McGarvey EL, Leon-Verdin M\& Bonnie RJ: The effect of community mental health services on hospitalization rates in Virginia. Psychiatr Serv 2011; 62:194-9. https://doi.org/10.1176/ps.62.2.pss6202_0194

51. Weiden PJ, Kozma C, Grogg A \& Locklear J Partial compliance and risk of rehospitalization among california medicaid patients with schizophrenia. Psychiatr Serv 2004; 55:886-91. doi:10.1176/appi.ps.55.8.886

52. Wykes T, Huddy V, Cellard C, McGurk SR \& Czobor P: A Meta-analysis of cognitive remediation for schizophrenia: Methodology and effect sizes. Am J Psychiatry 2011; 168: 472-85. https://doi.org/10.1176/appi.ajp.2010.10060855

53. Yanık M: Türkiye Ruh Sağllğı Sistemi Üzerine Değerlendirmeler ve Öneriler: Ruh Sağllğı Eylem Planı Önerisi. Psikiyatride Derlemeler, Olgular ve Varsaylmlar 2007: 1-80

54. Yıldiz M, Yüksel AG \& Erol A: Şizofrenide ruhsal ve toplumsal beceri ĕgitimi uygulamast grup eğitimi deneyimleri. Psychiatry in Türkiye 2005; 7:25-32

55. Yildız M, Kiras F, Incedere A, Esen D, Gürcan MB, Abut B et al.: Development of social functioning assessment scale (SFAS) for people with schizophrenia: Validity and reliability study. Anatolian J Psychiatry 2018; 19(Suppl 2): 29-38. doi: 10.5455/apd.2374

Correspondence:

Aydin Kurt, MD

Department of Psychiatry, Niğde Training and Research Hospital

51200, Niğde, Turkey

E-mail: aydinkurt20@yahoo.com 